\title{
Population-based cohort study: PROP1 gene mutations are the most prevalent cause of congenital multiple pituitary hormone deficiency in Lithuania
}

Ruta Navardauskaite ${ }^{1}$, Petra Dusatkova ${ }^{2}$, Barbora Obermannova ${ }^{2}$, Roland W. Pfaeffle ${ }^{3}$, Werner F. Blum $^{3}$, Dalia Adukauskiene ${ }^{4}$, Natalija Smetanina ${ }^{1}$, Ondrej Cinek ${ }^{2}$, Rasa Verkauskiene ${ }^{1}$, Jan Lebl²

${ }^{1}$ Institute of Endocrinology, Lithuanian University of Health Sciences, Medical Academy, Kaunas, Lithuania;

2Second Faculty of Medicine, Charles University in Prague and University Hospital Prague-Motol, Prague, Czech Republic; ${ }^{3}$ University Hospital for Children and Adolescents, University of Leipzig, Leipzig, Germany;

${ }^{4}$ Medical Academy, Lithuanian University of Health Sciences, Kaunas, Lithuania.

Background. Congenital multiple pituitary hormone deficiency (MPHD) may result from defects of transcription factors that govern the early pituitary development. The most prevalent are two mutation of PROP1 gene: the 296delGA and 150delA ${ }^{1,2}$.

\section{Methods:}

- Seventy five Lithuanian MPHD patients were tested for PROP1 defects by Sanger sequencing.

- Perinatal/postnatal growth data, hormonal profiles and pituitary size were analyzed.

\section{Conclusions:}

1. The population-based cohort of patients with $P R O P 1$ gene mutation is the largest described so far.

2. High prevalence of $P R O P 1$ defects in Lithuania is due to a founder effect of 296delGA mutation.

3. The 296delGA mutation of Lithuanian patients originating earlier than in another European countries patients ${ }^{3}$

(187.9 vs. 112 generations ago).

\section{Results:}

\section{DNA analyses results of PROP1 mutation}

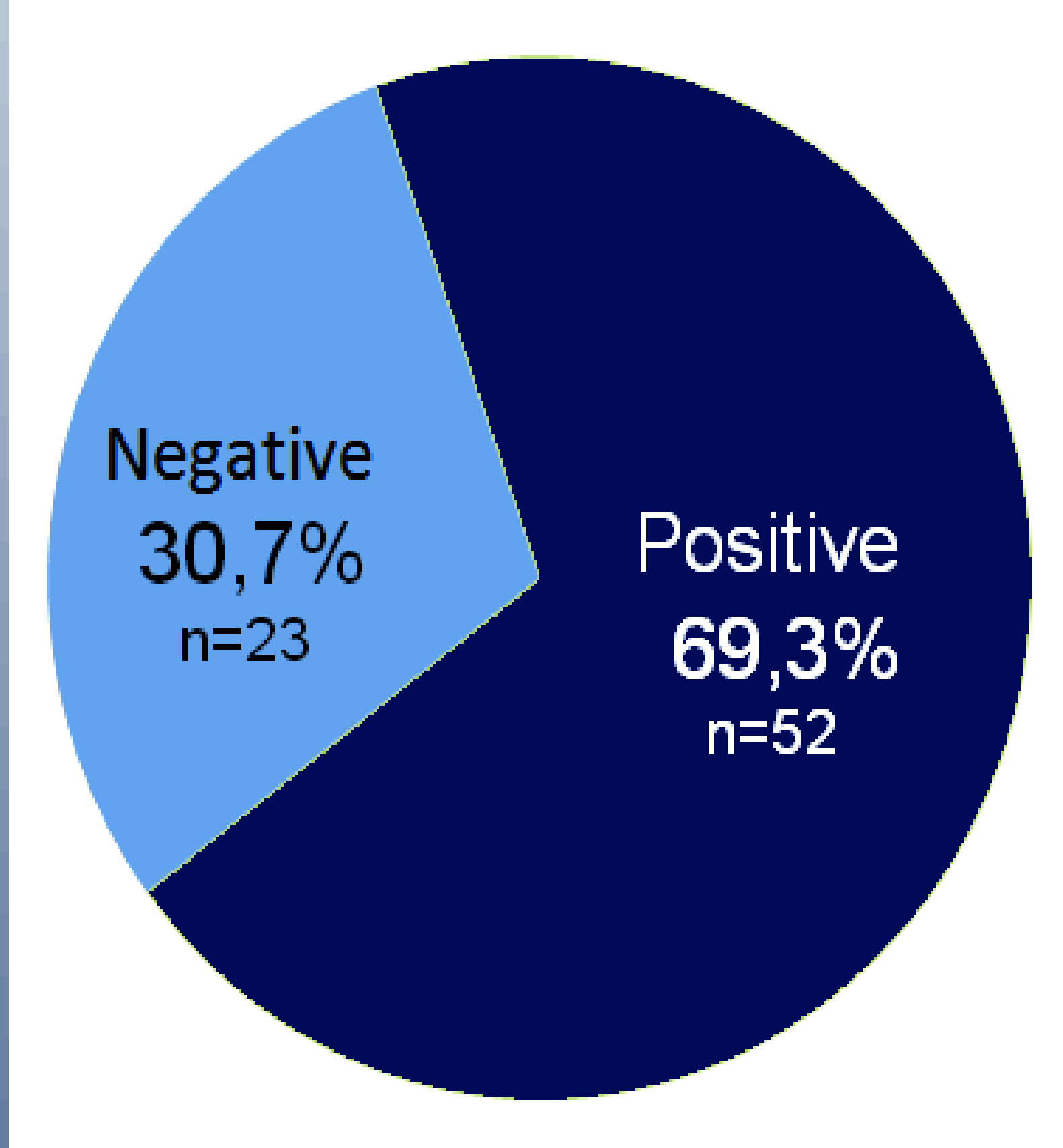

\section{Genotypes:}

50 patients - homozygote of 296delGA

1 patient - heterozygote of $296 \mathrm{delGA} / \mathrm{R} 71 \mathrm{H}$

1 patient - heterozygote of $296 \mathrm{delGA} / 150 \mathrm{del} A$

\section{Pituitary size}

- Pituitary height ranged from $16.6 \mathrm{~mm}(+20.2 \mathrm{SD})$ to 1.4 $\mathrm{mm}(-15.5 \mathrm{SD})$ and declined with age $\left(r^{2}=0.27\right.$, $P=0.001)$

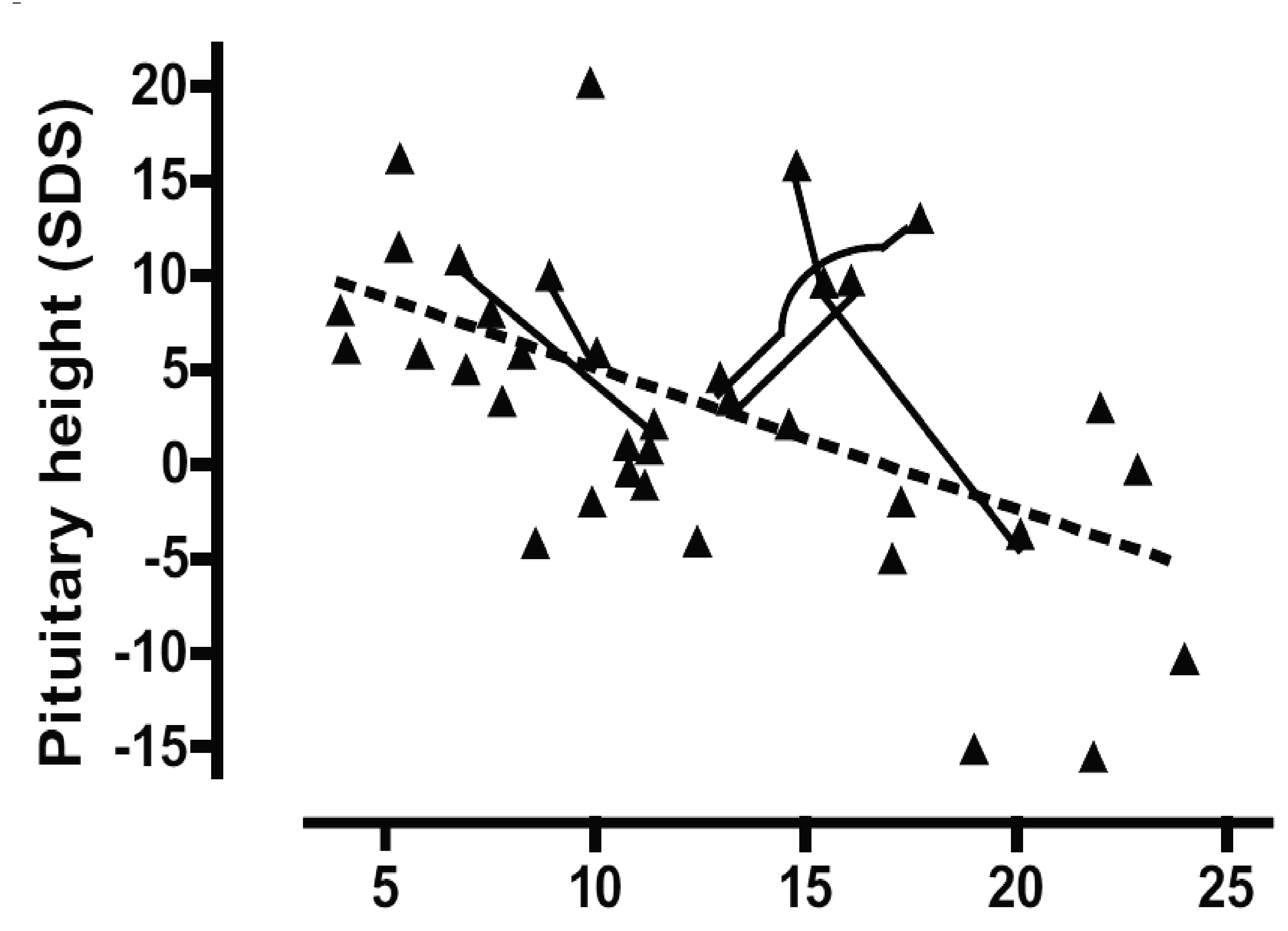

\section{Perinatal and postnatal data}

- $50 \%$ familial cases (ten sibling pairs and two sibling triples).

- The highest rate of PROP1 mutations among MPHD patients from populations studied so far (17.5 per million).

- The mutation carriers were found to share a common ancestor with the 296delGA mutation having arisen about $\mathbf{1 8 7 . 9}$ generations ago (range 156.8-229.5 generations).
- Patients' birth lengths and weights were normal.

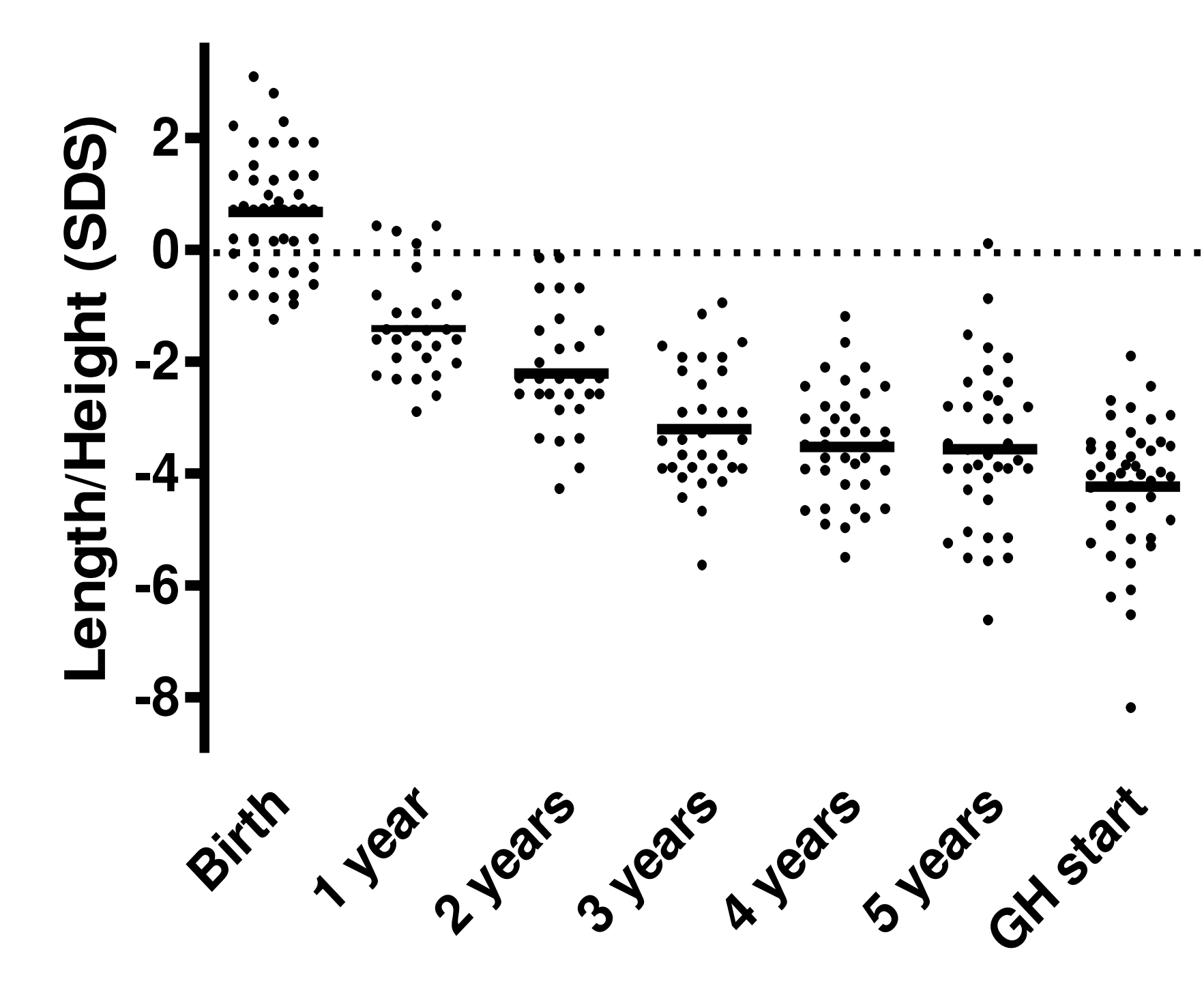

- Ages at diagnosis of hormones deficiencies.

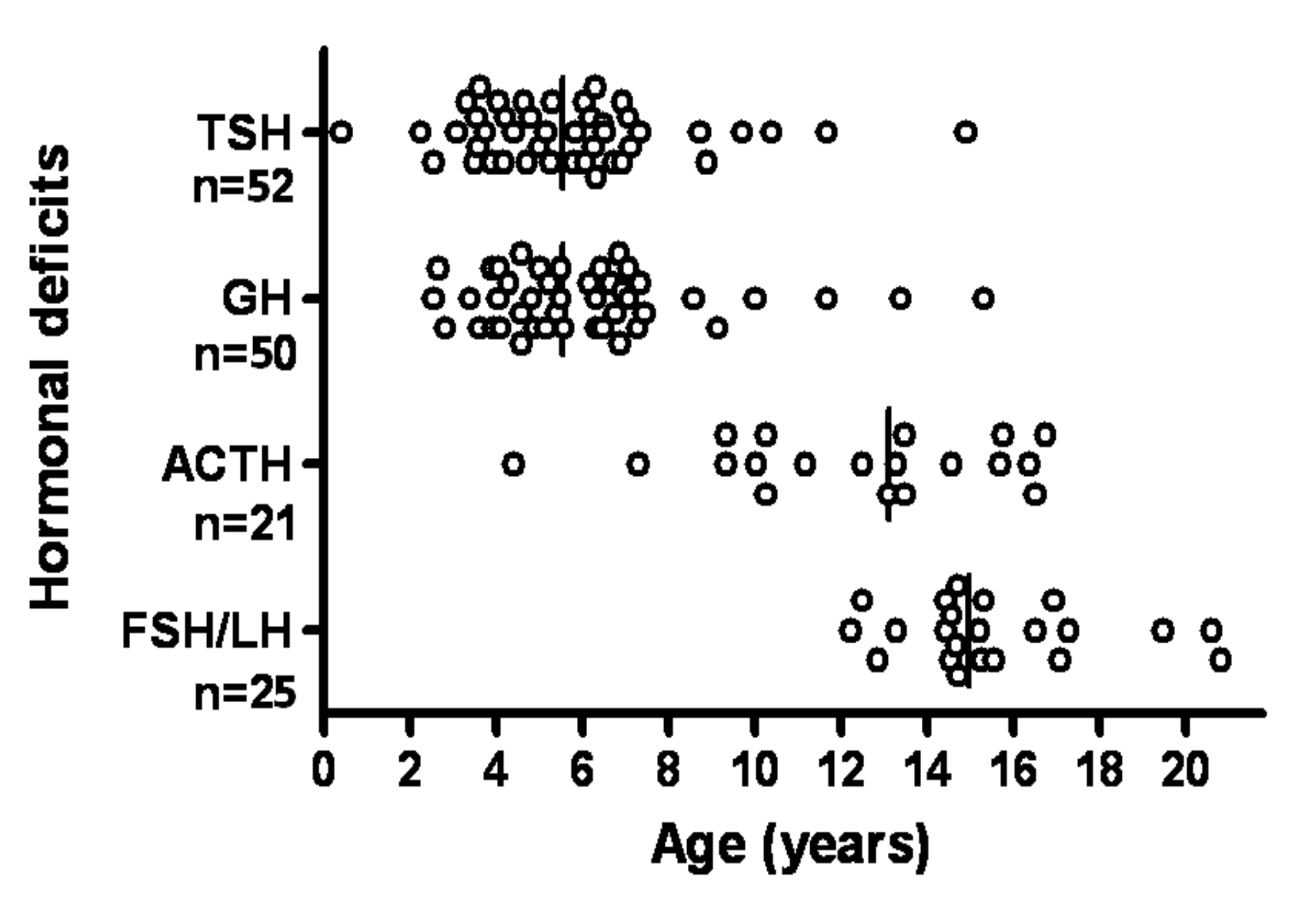

